\title{
Cordialidade em Esaú e Jacó, de Machado de Assis ${ }^{1}$
}

Teresinha V. Zimbrão da Silva | UFJF

Resumo: Estudo do romance Esaú e Jacó, de Machado de Assis, a partir do conceito de cordialidade de Sérgio Buarque de Holanda. Palavras-chave: identidade, cordialidade, Belle Époque.

\section{Introdução}

presente texto integrou um trabalho de pós-doutorado desenvolvido em 2006, que se propôs estudar Machado de Assis a partir da hipótese de que o escritor teria antecipado, na sua produção literária e crítica, as reflexões desenvolvidas por Sérgio Buarque de Holanda que resultaram no conceito de homem cordial exposto em Raizes do Brasil.

O conceito, desde a sua definição por Sérgio Buarque em 1936, tem se revelado muito produtivo como tentativa de se caracterizar aspectos importantes de uma possível identidade cultural do brasileiro. Contudo, carrega consigo polêmicas que importa comentar a fim de melhor definir a proposta do trabalho.

1. Uma versão deste trabalho foi apresentada no X Congresso Internacional da Abralic, realizado na UERJ, Rio de Janeiro, em agosto de 2006. 


\section{O Conceito e as polêmicas}

Principiemos pelo contra-argumento de que a cordialidade não seria exclusividade do brasileiro. Considerando que o próprio Sérgio Buarque sugeriu a possibilidade de se aplicar o conceito para o resto da América Latina, a objeção, prevista na origem mesma do conceito, não o invalidaria. O presente trabalho considera que o conceito de homem cordial constitui uma representação de identidade cultural sem a pretensão de que esta identidade seja exclusiva do brasileiro.

Em seguida, o contra-argumento de que uma sociedade violenta como a brasileira, que primeiro explorou o trabalhador escravo e depois o assalariado, não poderia ser cordial. Esta argumentação é motivada pela interpretação de cordial no seu significado corrente: amigo, bondoso, sincero, franco. Mas, como advertiu o próprio Sérgio Buarque, cordial deve ser tomado em seu sentido etmológico: pertencente ao coração. A inimizade e a violência podem ser tão cordiais quanto a amizade e a bondade, pois tanto umas como outras nascem do coração. ${ }^{3}$

Por fim, o contra-argumento de que o conceito constitui uma interpretação psicológica do brasileiro e, portanto, meta-histórica. Contudo, como notou Antônio Cândido na introdução à edição de 1973 de Raízes do Brasil, ${ }^{4}$ Sérgio Buarque de Holanda inspirou-se não só na psicologia, como também na história social e com um agudo senso das estruturas, procurando dar uma fundamentação sociológica à caracterização do homem cordial. A super valorização do aspecto psicológico do conceito incide num reducionismo que não permite notar sua historicidade.

O presente trabalho interpreta o conceito sublinhando os seguintes

2. Em Raízes do Brasil lê-se: "Ninguém ignora, porém, que o aparente triunfo de um princípio jamais significou no Brasil - como no resto da América Latina - mais do que o triunfo de um personalismo sobre outro. [...] A idéia de uma espécie de entidade imaterial e impessoal, pairando sobre os indivíduos e presidindo os seus destinos, é dificilmente inteligível para os povos da América Latina" (HOLANDA, 1973, p. 138).

3. Em Raizes do Brasil lê-se: "Cumpre ainda acrescentar que essa cordialidade, estranha, por um lado, a todo formalismo e convencionalismo social, não abrange, por outro, apenas e obrigatoriamente, sentimentos positivos e de concórdia. A inimizade bem pode ser tão cordial como a amizade, visto que uma e outra nascem do coração, procedem, assim, da esfera do íntimo, do familiar, do privado" (HOLANDA, 1973, p. 107).

4. HOLANDA, 1973, p. 21. 
aspectos: a cordialidade está próxima da afetividade da família patriarcal e distante da civilidade do Estado moderno, caracteriza-se pela espontaneidade da emoção íntima e não pelo convencionalismo da polidez cidadã, pressupõe antes relações pessoais e privadas, orientadas por simpatia e favor - resquícios do patriarcalismo - e não relações impessoais e públicas, orientadas por mérito e trabalho introduções da modernidade não consolidadas de todo no Brasil.

De particular interesse para o trabalho, é a caracterização da intelectualidade brasileira por Sérgio Buarque. Este sublinha que a indiferença do homem cordial à lei geral, quando esta contraria seus interesses particulares, demonstra, sobretudo, a sua incapacidade para aplicar-se a um objeto exterior a si mesmo. Nos intelectuais, este traço se revelaria através da aversão ao esforço do aprofundamento e, conseqüentemente, a satisfação com a aparente sabedoria, o prestígio da escrita retórica, o valor ornamental do diploma. Para o homem cordial, sempre interessado na satisfação pessoal, o trabalho do intelecto teria o seu fim no próprio intelectual e não na obra. ${ }^{5}$ O conto "A teoria do medalhão", publicado em 1882, corresponderia à versão machadiana mais explícita de uma equivalente caracterização da intelectualidade brasileira.

O presente trabalho concentra-se em Esaú e Jacó, a fim de explicitar algumas das reflexões machadianas que estamos relacionando ao conceito de cordialidade. No seu penúltimo romance, publicado em 1904, Machado de Assis nos introduz ao menos cordial de seus personagens: o narrador e diplomata Aires. Procuraremos mostrar que é a partir da definição deste como cordato (polido), justamente o oposto de cordial, que Machado de Assis constrói, por oposição, a cordialidade dos demais personagens e, portanto, antecipa as reflexões de Sérgio Buarque expostas em Raizes do Brasil.

Pois vejamos...

\section{O homem cordial e o homem cordato}

Principiemos por lembrar que Esaú e Jacó, ainda que seja um texto narrado na terceira pessoa, é definido no prólogo como o último volume das memórias de Aires. Machado de Assis constrói então a estranha situação narrativa

5. O conceito de homem cordial foi revisitado por João Cezar de Castro Rocha, que o inseriu num estudo crítico sobre o sistema intelectual no Brasil, intitulado Literatura e cordialidade (ROCHA, 1998). 
de um "eu" que se trata como um "ele". De fato, é em terceira pessoa que o narrador-diplomata sublinha o detalhe de ser um homem "extremamente cordato": Aires "[e]ra cordato, repito, embora esta palavra não exprima exatamente o que quero dizer. Tinha o coração disposto a aceitar tudo, não por inclinação à harmonia, senão por tédio à controvérsia".

Cordato, no contexto, significa se por de acordo para ser polido. De fato, lemos que Aires "usava sempre em concordar com o interlocutor, não por desdém da pessoa, mas para não dissuadir nem brigar".

Era, em todos os sentidos, um diplomata: "Imagina só que trazia o calo do ofício, o sorriso aprovador, a fala branda e cautelosa, o ar da ocasião, a expressão adequada, tudo tão bem distribuído que era um gosto ouvi-lo e vê-lo".

Lembremos que este diplomata passou uns trinta anos da sua vida no exterior, só visitando o país em ocasionais licenças. É o mais europeizado dos personagens machadianos, o mais civil e polido. Ora, a polidez comparece como um detalhe importante do retrato com que posa para a modernidade o homem civilizado. É suposta como uma grande virtude, apurada em longos anos de civilização e reivindicada como condição essencial para a vida em sociedade. Indispensável ao guarda-roupa do homem moderno, a polidez só será despida por ocasião da intimidade do lar, tal como Aires nos é descrito a fazer:

Não cuides que não era sincero, era-o. Quando não acertava de ter a mesma opinião, e valia a pena escrever a sua, escrevia-a [...], tendo para isso uma série de cadernos a que dava o nome de Memorial. Naquela noite escreveu estas linhas:

Noite em casa da família Santos [...]. Natividade e um Padre Guedes que lá estava, gordo e maduro, eram as únicas pessoas interessantes da noite. O resto insípido, mas insípido por necessidade, não podendo ser outra coisa mais que insípido. [...] Não acabo de crer como esta senhora, aliás tão fina, pode organizar noites como a de hoje. ${ }^{9}$

O mais europeizado dos personagens machadianos parece ter realizado a separação moderna entre o público e o privado. No fragmento, nós o

6. MACHADO DE ASSIS, 1997, p. 965.

7. MACHADO DE ASSIS, 1997, p. 1.057

8. MACHADO DE ASSIS, 1997, p. 964.

9. MACHADO DE ASSIS, 1997, p. 965-967. 
vemos despir a atitude cordata de salão para adotar a sinceridade devida a um diário íntimo (que só após a sua morte seria publicado). Neste diário, Aires qualifica as mesmas pessoas, a que em público tivera o trabalho de polidamente agradar, de "insípidos".

Em diversos momentos do romance, comparece sublinhada a oposição entre a atitude pública e a atitude privada de Aires. Vejamos alguns: em um diálogo mantido com Santos, quando fumava com este um charuto, o diplomata, enquanto "olhava mansamente" para o anfitrião, pensava consigo mesmo: "não podia negar a si mesmo a aversão que este lhe inspirava".

Há também o episódio da imprópria consulta noturna a Aires, por parte de Batista: este, como político conservador que era, queria saber a opinião do diplomata se devia ou não aceitar o convite dos liberais para assumir a presidência de uma província. Aires ouvia e "escondia o espanto... Convidado assim àquela hora... Uma profissão de fé política...". A calma aparente do diplomata antes escondia uma impaciência que ele civilizadamente procurava controlar. O impróprio da situação era demais até para a sua cordata polidez. "Quando Aires se achou na rua, só, livre, solto, entregue a si mesmo, sem grilhões, nem considerações, respirou largo" .

Ou ainda o caso de Flora: esta pedira a Aires que dissuadisse o pai da idéia de deixar a corte e ir para a província e o diplomata cordato prometeu intervir, só que no íntimo, "achou tão absurdo este pedido, que esteve quase a rir, mas conteve-se bem". Contudo, diante da oportunidade proporcionada pela consulta de Batista, aconselhou então a este exatamente o contrário do que antes prometera à filha - e, portanto, sendo agora cordato para com o pai, a quem interessava aceitar o cargo na província.

Enfim, o europeizado Aires alcança satisfazer cordatamente a todos, e sobressai nestas cenas como o único a dominar com maestria as leis modernas do convívio social. De fato, notemos que os outros personagens comparecem justamente a infringir estas leis quando exteriorizam, em contraste com a atitude cordata do Conselheiro, uma disposição tanto para controvérsias apaixonadas (os "insípidos" da noite em casa de Santos discutiam com paixão sobre a adivinha do morro do Castelo), quanto para revelações íntimas (como nos exemplos de Batista e Flora), ambas as atitudes tidas como impróprias à conversa polida de salão.

10. MACHADO DE ASSIS, 1997, p. 1.012 .

11. MACHADO DE ASSIS, 1997 , p. 1.017

12. MACHADO DE ASSIS, 1997, p. 1.015 . 
A atitude cordata de Aires demonstra a moderna impessoalidade com que este conduz as suas relações sociais, já, a atitude dos demais personagens, explicita um arcaísmo de um país patriarcalista que, insistindo na pessoalidade de todos os vínculos, não faz distinções entre o espaço público e o privado. Aires se vê então às voltas com casos como os de Flora e Batista, a pedirem ambos um conselho pessoal a ele, praticamente um estranho. Lembremos que o diplomata considerava esta sociedade como composta por "gente estranha" ${ }^{13}$ e não por amigos e ele só os ouvia por "imposição de sociedade".

É ainda significativo que estes dois personagens não sejam os únicos a reivindicar ao Conselheiro Aires, a intimidade que acompanha o papel de conselheiro (título que deveria ser, por convenção, apenas simbólico). De fato, tanto Batista e Flora, quanto Natividade, Santos, Pedro, Paulo e até Custódio recorrem aos conselhos do Conselheiro. E se este os recebe em público com polidez, quando na intimidade do seu Memorial, os deprecia, atribuindo-lhes a condição de "insípidos", além da epígrafe "anima mal nata".

A esta altura nos interessa sublinhar que o romance machadiano Esaú e Jacó, de fato, sugere que, na sociedade brasileira, há constante invasão do espaço público pelo privado (existem outros exemplos a serem citados, mas que extrapolam os limites do presente trabalho). ${ }^{15}$ Pois este importante traço identitário é determinante nas reflexões desenvolvidas por Sérgio Buarque de Holanda em Raizes do Brasil. No capítulo "O homem cordial", Sérgio Buarque denomina este "traço definitivo do caráter brasileiro", definido pelos "padrões de convívio humano, informados no meio rural e patriarcal", de "cordialidade". Expressão que deveria ser tomada em seu "sentido exato e estritamente etimológico", para designar um sentimento nascido do coração, "procedendo assim da esfera do íntimo, do familiar, do privado".

Machado então antecipa, através da oposição que constrói entre a moderna impessoalidade do europeizado Aires, atualizada na atitude cordata ou

13. MACHADO DE ASSIS, 1997, p. 989.

14. MACHADO DE ASSIS, 1997, p. 1.015

15. O registro machadiano da não distinção, por parte do brasileiro, entre os espaços público e privado já foi estudado por Luiz Costa Lima no ensaio "Machado e a inversão do veto" em O controle do imaginário (LIMA, 1984, p. 242-261).

16. HOLANDA, 1975 , p. 106-107. 
polida deste, e a arcaica pessoalidade dos outros personagens, atualizada por seu turno na atitude cordial destes últimos, a reflexão sobre uma possível "raiz do Brasil", a qual mais tarde seria definida por Sérgio Buarque, junto com a própria distinção entre ambas as atitudes: "a atitude polida consist[e] precisamente em uma espécie de mímica deliberada de manifestações que são espontâneas no "homem cordial": é a forma natural e viva que se converteu em fórmula".

De fato, o seu estudo sublinha a distância que separa os dois conceitos, a polidez e a cordialidade, e ainda o quanto que o modelo de convivência social em vigor no Brasil, ao destoar do primeiro, distancia o país da ritualística impessoalidade com que o indivíduo aprendeu a se disfarçar na sociedade moderna:

Nenhum povo está mais distante dessa noção ritualística da vida que o brasileiro. Nossa forma ordinária de convívio social é no fundo justamente o contrário da polidez. [...] a polidez é de algum modo, organização de defesa ante a sociedade. Detém-se na parte exterior, epidérmica do indivíduo, podendo mesmo servir, quando necessário de peça de resistência. Equivale a um disfarce que permitirá a cada qual preservar intatas sua sensibilidade e emoções. ${ }^{18}$

Pois é este impessoal disfarce, em contraste com a pessoalidade dos outros personagens, que estamos presenciando o europeizado Aires a vestir em Esaú e Jacó. Machado constrói então um personagem que no convívio social, procura disfarçar as suas emoções mais íntimas, as quais serão transcritas em um diário, a ser publicado somente depois da sua morte, quando este não mais precisar se defender diante desta sociedade.

Ao mesmo tempo, que apresenta um personagem "extremamente cordato", Machado apresenta seus outros personagens com traços de cordialidade. A invasão do espaço público pelo privado na sociedade brasileira não escapou ao escritor e é registrada no seu penúltimo romance. Estas são algumas das reflexões machadianas que estamos relacionando ao conceito do homem cordial de Sérgio Buarque de Holanda.

17. HOLANDA, 1973, p. 107.

18. HOLANDA, 1973, p. 107. 
Abstract: In this work we study the novel Esaú e Jacó by Machado de Assis, considering the concept of "cordialidade" by Sérgio Buarque de Holanda. Keywords: identity, cordiality, Belle Époque.

$$
\text { Referências }
$$

HOlANDA, Sérgio Buarque de. Raizes do Brasil. Rio de Janeiro: José Olympio, 1973 [1936].

LIMA, Luiz Costa. O controle do imaginário. São Paulo: Brasiliense, 1984.

MACHADO DE ASSIS, Joaquim Maria. Esaú e Jacó. Afrânio Coutinho (Org.). Obra Completa, v. I. Rio de Janeiro: Nova Aguilar, 1997 [1904].

ROCHA, João Cezar de Castro. Literatura e cordialidade. Rio de Janeiro: Eduerj, 1998. 